however, compared to the control group patients with COPD demonstrated significantly lower scores in memory $(\mathrm{p}<0.01)$, attention $\quad(p=0.013)$ fluency $(p=0.002)$ and language $(p=0.004)$ domains. Interestingly the pattern of cognitive impairment in patients with COPD was similar but less severe compared to patients with $\mathrm{AD}$ who demonstrated significantly lower total ACE-III scores $(\mathrm{p}<0.001)$.

Conclusions This study demonstrates a high burden of cognitive impairment in patients with COPD. Interestingly the cognitive domains of memory, attention, fluency and language seem to be predominantly affected in this population. These findings further our understanding of cognitive impairment in patients with COPD, with patients exhibiting a similar but less severe pattern of cognitive impairment to that seen in the $\mathrm{AD}$ group.

\section{P98 GREY MATTER ATROPHY, RETINAL VESSEL DILATATION \& REDUCTION IN AORTIC DISTENSIBILITY IN COPD: THE RELATIONSHIP BETWEEN MULTI-ORGAN VASCULAR MEASURES}

${ }^{1} \mathrm{JW}$ Dodd, ${ }^{2} \mathrm{CA}$ Spilling, ${ }^{3} \mathrm{M}$-PK Bajaj, ${ }^{3} \mathrm{DR}$ Burrage, ${ }^{3} \mathrm{~S}$ Ruickbie, ${ }^{4} \mathrm{GJ}$ McKay, ${ }^{5} \mathrm{C}$ BucciarelliDucci, ${ }^{3}$ EH Baker, ${ }^{2}$ TR Barrick, ${ }^{3}$ PW Jones. ${ }^{1}$ Academic Respiratory Unit, Southmead Hospital, Bristol, UK; ${ }^{2}$ Neuroscience Research Centre, Molecular and Clinical Sciences Research Institute, St George's, University of London, London, UK; ${ }^{3}$ Clinical Pharmacology, Institute of Infection and Immunity Institute, St George's, University of London, London, UK; ${ }^{4}$ Centre for Public Health, Queens University, Belfast, UK; ${ }^{5}$ Bristol Heart Institute, University Hospitals Bristol, Bristol, UK

\subsection{6/thoraxjnl-2017-210983.240}

Background COPD is linked to risk of MI, stroke and white matter brain lesions, but there is no recognised method of identifying those who go on to have acute vascular events. It also remains unclear if vascular risk in COPD is truly independent of smoking. The Novel Vascular Manifestations of COPD (NoVasC) study was designed to address this limitation through direct comparison of COPD patients and smoking controls using multimodal brain MRI, retinal photography, cardiac MRI (CMR) and aortic stiffness in addition to cognitive and disease severity measures.

Methods MR brain volumes, diffusion, blood flow and white matter lesions were acquired for 27 COPD patients (age 67 $\pm 8,41 \%$ male, pack years $39 \pm 21, \mathrm{FEV}_{1} 58 \% \pm 18 \%$ predicted)

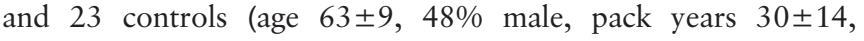
$\mathrm{FEV}_{1} 101 \% \pm 19 \%$ predicted). CMR of LV and RV function, volumes and aortic distensibility were captured using a 3-Telsa MR scanner. Pulse wave velocity and augmentation index were acquired using Vicorder. Retinal fundus photographs were analysed using validated automated software (SIVA). Analyses adjusted for differences in age, gender, blood pressure and pack years smoked.

Results Significant differences in grey matter volume $(p=0.004)$, retinal vessels $(p=0.005)$ and CMR $(p=0.01)$ were identified in COPD (Table 1). There was significant correlation between grey matter volume and BMI ( $\mathrm{r}=-0.42$ $\mathrm{p}=0.005$ ) only. White matter lesion volume was associated with FEV1/FVC and creatinine $(\mathrm{r}=0.29 \quad \mathrm{p}=0.048$ and $r=-0.33 \mathrm{p}=0.027)$. Cerebral blood flow was associated with arterial $\mathrm{pH}$ in $\operatorname{COPD}(\mathrm{r}=-0.49 \mathrm{p}=0.019)$. There were no significant associations identified between other MR brain, cognition, disease severity or retinal measures. Significant correlations were identified between $\mathrm{CMR}$ and white matter damage (DTI $\mathrm{r}=0.50 \mathrm{p}=0.001)$ and FEV1/FVC $(\mathrm{r}=0.447$ $\mathrm{p}=0.003)$ and retinal measures with $\mathrm{FEV} 1 \%$ pred $(\mathrm{r}=-0.43$ $\mathrm{p}=0.006)$.

Conclusions Grey matter atrophy, retinal vessel dilatation, and aortic distensibility are present in COPD. White matter lesions volume is associated with lung function but there was no relationship between other MRI brain measures, cognition or disease severity. Non-invasive vascular measures of retinal vessels and cardiac MR appear to relate to lung function and white matter damage and warrant further investigation in larger longitudinal studies of vascular events in COPD.

Abstract P98 Table 1 COPD group vs. smoker controls ANOVA corrected for age, gender, mean arterial blood pressure and pack years smoked

\begin{tabular}{|c|c|c|c|c|c|c|}
\hline & & $\begin{array}{l}\text { Sum of } \\
\text { Squares }\end{array}$ & df & $\begin{array}{l}\text { Mean } \\
\text { Square }\end{array}$ & $F$ & Sig. \\
\hline Normalised White Matter & Between & 0.625 & 1 & 0.625 & 0.115 & 0.736 \\
\hline Volume & Groups & & & & & \\
\hline Voxel based & Within & 260.862 & 48 & 5.435 & & \\
\hline \multirow[t]{2}{*}{ Morphometry. (VBM) } & Groups & & & & & \\
\hline & _Total & 261.487 & 49 & & & \\
\hline Normalised Grey Matter & Between & 19.169 & 1 & 19.169 & 9.181 & 0.004 \\
\hline \multirow[t]{4}{*}{ Volume. VBM } & Groups & & & & & \\
\hline & Within & 100.216 & 48 & 2.088 & & \\
\hline & Groups & & & & & \\
\hline & Total & 119.385 & 49 & & & \\
\hline \multirow[t]{5}{*}{ Retina Factor } & Between & 7.589 & 1 & 7.589 & 8.925 & 0.005 \\
\hline & Groups & & & & & \\
\hline & Within & 37.411 & 44 & 0.850 & & \\
\hline & Groups & & & & & \\
\hline & Total & 45.000 & 45 & & & \\
\hline \multirow[t]{5}{*}{ Cardiac MR Factor } & Between & 6.204 & 1 & 6.204 & 7.015 & 0.011 \\
\hline & Groups & & & & & \\
\hline & Within & 39.796 & 45 & 0.884 & & \\
\hline & Groups & & & & & \\
\hline & Total & 46.000 & 46 & & & \\
\hline \multirow[t]{5}{*}{ Cerebral Diffusion Tensor } & Between & 2.283 & 1 & 2.283 & 2.345 & 0.132 \\
\hline & Groups & & & & & \\
\hline & Within & 46.717 & 48 & 0.973 & & \\
\hline & Groups & & & & & \\
\hline & Total & 49.000 & 49 & & & \\
\hline \multirow[t]{5}{*}{ Cerebral Blood Flow } & Between & 0.454 & 1 & 0.454 & 0.449 & 0.506 \\
\hline & Groups & & & & & \\
\hline & Within & 48.546 & 48 & 1.011 & & \\
\hline & Groups & & & & & \\
\hline & Total & 49.000 & 49 & & & \\
\hline \multirow[t]{5}{*}{ White Matter Lesions } & Between & 0.412 & 1 & 0.412 & 0.407 & 0.526 \\
\hline & Groups & & & & & \\
\hline & Within & 48.588 & 48 & 1.012 & & \\
\hline & Groups & & & & & \\
\hline & Total & 49.000 & 49 & & & \\
\hline
\end{tabular}

†p value $<0.01$ 


\section{P99}

CLINICAL CHARACTERISTICS AND MANAGEMENT OF DUAL ASTHMA AND CHRONIC OBSTRUCTIVE PULMONARY DISEASE (COPD) DIAGNOSIS IN PRIMARY CARE; RESULTS FROM THE WELSH NATIONAL COPD PRIMARY CARE AUDIT

${ }^{1} \mathrm{M}$ Fisk, ${ }^{2} \mathrm{~V}$ McMillan, ${ }^{3} \mathrm{~J}$ Brown, ${ }^{2} \mathrm{~J}$ Holzhauer-Barrie, ${ }^{2} \mathrm{MS}$ Khan, ${ }^{4} \mathrm{~N}$ Baxter, ${ }^{5} \mathrm{CM}$ Roberts. ${ }^{1}$ Barts Health NHS Foundation Trust, London, UK; ${ }^{2}$ Royal College of Physicians, London, UK; ${ }^{3}$ Royal Free NHS Foundation Trust, London, UK; ${ }^{4}$ Royal College of Physicians and NHS Southwark CCG, London, UK; ${ }^{5}$ Clinical Effectiveness and Evaluation Unit, Royal College of Physicians and Queen Mary University of London, London, UK

10.1136/thoraxjnl-2017-210983.241

Introduction Asthma and COPD are two common conditions that are diagnosed and managed in primary care. However, it is currently unknown whether patients with a dual diagnosis of asthma and COPD differ from patients with COPD alone, based on UK general practice records. We sought to evaluate the clinical characteristics and management in primary care of patients with a dual diagnosis of asthma and COPD, compared to those with COPD alone, using data from the first Welsh national COPD primary care audit.

Methods The Welsh national COPD primary care audit prospectively collected data of patients registered with COPD from $61 \%$ of GP practices in Wales covering January 2014March 2015. This analysis compared 5682 patients with a current co-diagnosis of asthma to 42301 patients with COPD alone.

Results There were no significant differences in age $(71 \pm 12$ years for both), body mass index $(27.54 \pm 6.40$ vs $27.42 \pm 6.32$ $\left.\mathrm{kg} / \mathrm{m}^{2}\right)$, gender $(48 \%$ vs $47 \%$ female), or smoking status (33.1\% vs $33.8 \%$ current smoker) between patients with a codiagnosis of asthma vs patients with COPD alone, respectively. Spirometry, exacerbation frequency and reported breathlessness were also similar $\left[\left(\mathrm{FEV}_{1}: 1.49 \pm 0.64\right.\right.$ vs $1.50 \pm 0.63$ litres, $\mathrm{p}=0.65), \quad($ exacerbations: $7.36 \pm 8.41$ vs $7.24 \pm 8.73, \mathrm{p}=0.36$ ), (MRC: $2.62 \pm 1.02$ vs $2.59 \pm 1.01, \mathrm{p}=0.10$ )]. However, patients with a co-diagnosis of asthma compared to COPD alone, were less likely to receive influenza vaccination $(80.2 \%$ vs $81.4 \%, \mathrm{p}<0.001)$, pulmonary rehabilitation $(15.9 \%$ vs $18.9 \%$, $\mathrm{p}<0.001)$, 3-6 month review $(1.6 \%$ vs $2.6 \%, \mathrm{p}<0.001)$ or smoking cessation $(67.2 \%$ vs $68.4 \%, \mathrm{p}=0.07)$, but were more likely to receive pharmacology therapies: long acting beta agonist (LABA): $28.8 \%$ vs 25.8\%, p<0.001, inhaled corticosteroids (ICS): $51.7 \%$ vs $48.2 \%, \quad \mathrm{p}<0.001$, long acting muscarinic antagonist: $69 \%$ vs $65.8 \%, \mathrm{p}<0.001$, and combined LABA/ICS inhaler: $70.6 \%$ vs $68.5 \%, \mathrm{p}<0.001$.

Conclusions Patients with a dual diagnosis of asthma and COPD compared to patients with COPD alone, received less non-pharmacological COPD management in primary care, despite being on more inhaled medication and having similar levels of COPD severity. These are clinically important data from the Welsh national COPD primary care audit and suggest that quality improvement actions focused on COPD care for patients with a dual diagnosis of asthma and COPD are required.

\section{P100 RISK OF STROKE ASSOCIATED WITH ACUTE EXACERBATIONS OF CHRONIC OBSTRUCTIVE PULMONARY DISEASE (COPD): A SELF-CONTROLLED CASE SERIES}

OL Connell, KJ Rothnie, JK Quint. NHLI, Imperial College London, London, UK

\subsection{6/thoraxjnl-2017-210983.242}

Introduction and Objectives Chronic Obstructive Pulmonary Disease (COPD) patients are at increased risk of cardiovascular disease. Previous studies have suggested that acute exacerbations of COPD (AECOPD) are associated with an increased risk of stroke in COPD patients. We aimed to characterise the size and duration of the increased risk of stroke following AECOPD as well as factors that modify the risk.

Methods Using data from the Clinical Practice Research Datalink linked with Hospital Episode Statistics, we conducted a self-controlled case series on COPD patients who had an AECOPD and a stroke. Fixed-effects conditional Poisson regression was utilised to estimate the incidence rate ratio (IRR) of stroke in the 91 day period following AECOPD compared with stable periods. The 91 day period was also segmented into shorter time periods, which were compared with stable periods in order to determine how the risk of stroke post-AECOPD changes over time. We stratified by various factors (including AECOPD severity, exacerbation frequency, cardiovascular disease history, and cardiovascular and respiratory drug prescription) to identify which modified this risk.

Results 3,466 COPD patients were identified as having at least one AECOPD and a first stroke during the study period. We observed an increased risk of stroke in the 91 day period following AECOPD compared with stable periods (IRR $=1.47$, 95\% CI: 1.36-1.59), which peaked on days 4-7 (IRR=1.93, 95\% CI: 1.57-2.37), not returning to baseline until after 91 days post-AECOPD. This increased risk was observed for ischaemic strokes only ( $\mathrm{IRR}=1.51,95 \% \mathrm{CI}$ : 1.39-1.65). The relative risk of ischaemic stroke post-AECOPD was significantly higher for those with lower exacerbation frequency, and significantly lower for aspirin users and those with a previous angina diagnosis.

Conclusions There is a 1.47 -fold increased risk of stroke in the 91 days following AECOPD which peaks on days 4-7 and does not return to baseline until after 91 days postAECOPD. This may be used to inform physicians when their patients are at greatest risk of stroke following AECOPD and may provide the basis of future interventions such as the introduction of aspirin to reduce this risk and possibly reduce mortality in COPD patients. 